\title{
Scala Tympani Cochleostomy I: Results of a Survey
}

Oliver F. Adunka, MD; Craig A. Buchman, MD

Objective: To assess current surgical techniques for scala tympani cochlear implantation among North American surgeons.

Material: A survey was distributed to all cochlear implant surgeons participating in the 2006 William House Cochlear Implant Study Group in Toronto, Canada. Participants were asked to anonymously identify their routine surgical practices. Images of trans-facial recess approaches to the round window and cochlear promontory were used in a multiple-choice fashion to assess the surgeon's typical exposure and cochleostomy location. Returned questionnaires were electronically processed and evaluated.

Results: Fifty-five (75\%) of 73 returned surveys had adequate data validity and availability. Landmark identification and preferred cochleostomy locations varied greatly. About 20\% of surgeons selected cochleostomy locations superior to the round window membrane. Cochleostomy size and location appeared to be influenced by surgical experience and whether or not the round window overhang was drilled off.

Conclusion: This survey clearly documents marked variations in surgical techniques for scala tympani cochlear implantation. Future studies should more clearly define the surgical anatomy of this region for appropriate placement of a scala tympani cochleostomy. These findings may ultimately have an impact on hearing and neural preservation cochlear implant surgeries.

Key Words: Survey, cochlear implant, surgery, cochleostomy, scala tympani.

Laryngoscope, 117:2187-2194, 2007

\section{INTRODUCTION}

For uncomplicated cochlear implantation, a number of factors make scala tympani (ST) the ideal location for most electrode arrays. First ST has a slightly larger diameter than scala vestibuli (SV) and can thus better accom-

From the Department of Otolaryngology-Head \& Neck Surgery, University of North Carolina at Chapel Hill, Chapel Hill, North Carolina, U.S.A. 19, 2007.

Editor's Note: This Manuscript was accepted for publication June

Send correspondence to Craig A. Buchman, MD, FACS, Professor Department of Otolaryngology-Head \& Neck Surgery, University of North Carolina at Chapel Hill, 101 Manning Drive, CB 7070, Chapel Hill, NC 27599, U.S.A. E-mail: buchman@med.unc.edu

DOI: 10.1097/MLG.0b013e3181453a6c modate the electrode array. ${ }^{1}$ This location allows for electrode insertion below the fragile cochlear duct and in close proximity to the spiral ganglion cell bodies. Importantly, SV and scala media (SM) are separated only by Reissner's membrane, a fragile two-cell layered structure. Thus, electrode insertions into SV generally result in greater intracochlear trauma. ${ }^{2}$ Another reason for using ST instead of $\mathrm{SV}$ is the relatively convenient relationship of ST to the round window membrane.

William F. House was among the first to use the trans-facial recess route for permanent cochlear implantation into the scala tympani via the round window membrane in the early 1970s. ${ }^{3}$ For the single-channel device, the round window provided an adequate angle for electrode insertion into the first few millimeters of the basal segment of the cochlea. ${ }^{4}$ Subsequently, deeper insertions of multi-electrode arrays became the target in an effort to access the tonotopical arrangement of the cochlea. ${ }^{5}$ Unfortunately, these early electrode arrays generated relatively high resistive forces to insertion. Using the round window membrane, the angle of insertion frequently resulted in electrode buckling and associated trauma. Thus, a separate cochleostomy site was advocated in an effort to use a straighter, in-line, electrode insertion. ${ }^{6}$ The straight insertion afforded via the separate cochleostomy accomplished the desired greater insertion depths while minimizing both electrode and cochlear trauma. ${ }^{7}$

Few studies have described the surgical anatomy of the promontory region relevant to cochlear implantation..$^{8,9}$ No studies have correlated topographical, surgical cochleostomy locations with associated intracochlear trauma. Moreover, the functional consequences of various cochleostomy openings are just beginning to be explored. In a recent study, scala tympani electrode placement was found to be significantly associated with improved speech perception results. ${ }^{10}$ With the recent advent of bimodalelectrical and acoustic stimulation within the same ear, hearing preservation in cochlear implantation has taken on even greater importance. ${ }^{11,12}$ While the etiology of implant-induced hearing loss remains speculative, most believe that precise location of the cochleostomy within the scala tympani is of paramount importance..$^{9,13,14}$

It is commonly held that to enter the scala tympani, an anterior and inferior cochleostomy is needed in relation to the round window membrane. In an excellent review by 
TABLE I.

Responses for Each Valid Questionnaire.

\begin{tabular}{|c|c|c|c|c|c|c|c|c|c|c|c|c|c|}
\hline Questionnaire & $\begin{array}{c}1 \\
\text { Implants } \\
\text { (n) }\end{array}$ & Drill $†$ & $\begin{array}{c}3 \\
\text { Burr } \\
\text { Size† }\end{array}$ & $\begin{array}{c}4 \\
\text { Facial } \\
\text { Nerve }\end{array}$ & $\begin{array}{c}5 \\
\text { Chorda } \\
\text { Tympani }\end{array}$ & $\begin{array}{c}6 \\
\text { Round } \\
\text { Window }\end{array}$ & $\begin{array}{c}7 \\
\text { Size } \\
\text { Opening }\end{array}$ & $\begin{array}{c}8 \\
\text { Drill } \\
\text { Round } \\
\text { Window }\end{array}$ & $\begin{array}{c}9 \\
\text { Round } \\
\text { Window } \\
\text { Insertions }\end{array}$ & $\begin{array}{c}10 \\
\text { Image } \\
1\end{array}$ & Exposure & $\begin{array}{c}11 \\
\text { Image } \\
2\end{array}$ & $\begin{array}{c}12 \\
\text { Image } \\
3\end{array}$ \\
\hline 2 & $50+$ & Skeeter & 0.6 & No & Yes & Yes & 1.0 & Yes & No & 6 & Yes & 7 & 7 \\
\hline 3 & $30-50$ & Midas rex & 1.0 & No & Yes & Yes & 1.0 & Yes & No & 6 & No & & 8 \\
\hline 6 & $30-50$ & Anspach & 1.0 & Yes & No & Yes & 1.0 & Yes & Yes & 10 & No & $7^{\star}$ & 10 \\
\hline 7 & $0-10$ & Anspach & 1.0 & Yes & No & No & 1.5 & No & No & 2 & Yes & NA & 4 \\
\hline 8 & $0-10$ & Anspach & 1.0 & No & Yes & No & 1.0 & No & No & 6 & No & & 8 \\
\hline 9 & $50+$ & Anspach & 1.0 & Yes & Yes & Yes & 1.0 & No & No & 9 & No & & 9 \\
\hline 10 & $50+$ & Skeeter & 0.6 & Yes & No & No & 0.8 & Yes & No & 9 & No & & 9 \\
\hline 15 & $10-20$ & Medtronic & 1.0 & No & Yes & No & 1.2 & No & No & 3 & No & $2^{*}$ & 7 \\
\hline 16 & $0-10$ & Medtronic & 1.0 & Yes & Yes & No & 1.5 & Yes & No & 2 & No & & 7 \\
\hline 17 & $20-30$ & Anspach & 1.0 & No & No & Yes & 1.2 & Yes & No & 6 & No & & 7 \\
\hline 18 & $20-30$ & Anspach & 1.0 & Yes & Yes & Yes & 1.2 & Yes & No & 6 & No & & 7 \\
\hline 19 & $20-30$ & Anspach & 1.0 & Yes & Yes & No & 1.2 & Yes & No & 9 & No & $4^{*}$ & 9 \\
\hline 20 & $30-50$ & Stryker & 1.0 & No & Yes & Yes & 1.5 & Yes & No & 9 & Yes & 5 & 9 \\
\hline 21 & $20-30$ & Linvatec & 1.0 & Yes & Yes & No & 1.2 & Yes & No & 2 & No & & 5 \\
\hline 22 & $20-30$ & Skeeter & 1.2 & Yes & No & No & 2.0 & Yes & No & 6 & No & & 9 \\
\hline 23 & $50+$ & NA & 0.6 & Yes & Yes & No & 1.0 & No & No & 14 & No & & 8 \\
\hline 24 & $20-30$ & Anspach & 1.5 & No & No & Yes & 1.5 & Yes & No & 6 & No & & 9 \\
\hline 31 & $20-30$ & Anspach & 1.0 & No & Yes & Yes & 1.5 & No & No & 9 & No & & 11 \\
\hline 32 & $10-20$ & NA & 1.0 & Yes & No & No & 1.2 & No & No & 7 & No & & 8 \\
\hline 33 & $0-10$ & Linvatec & 1.0 & Yes & Yes & No & 1.0 & No & No & 2 & Yes & 8 & 7 \\
\hline 34 & $20-30$ & Skeeter & 1.0 & Yes & Yes & Yes & 1.2 & No & Yes & 3 & Yes & 7 & 1 \\
\hline 35 & $10-20$ & Anspach & 1.0 & No & No & Yes & 1.2 & No & No & 2 & No & & 8 \\
\hline 36 & $20-30$ & Anspach & 1.0 & No & No & No & 1.0 & Yes & Yes & 6 & No & $8^{*}$ & 7 \\
\hline 37 & $10-20$ & Medtronic & 1.0 & No & No & Yes & 1.2 & Yes & No & 3 & No & & 7 \\
\hline 38 & $30-50$ & Anspach & 1.0 & Yes & Yes & No & 1.5 & No & No & 13 & Yes & 8 & 7 \\
\hline 39 & $10-20$ & Anspach & 1.0 & No & No & No & 1.5 & Yes & No & 9 & Yes & 7 & 7 \\
\hline 40 & $10-20$ & Stryker & 0.8 & Yes & No & Yes & 2.0 & Yes & Yes & 5 & No & & 7 \\
\hline 41 & $10-20$ & Anspach & 1.5 & No & No & Yes & 1.5 & Yes & No & 6 & Yes & 7 & 5 \\
\hline 42 & $20-30$ & Anspach & 1.0 & Yes & No & Yes & 1.0 & No & No & 10 & No & & 9 \\
\hline 43 & $0-10$ & Anspach & 1.0 & Yes & No & No & 1.5 & No & No & 5 & Yes & 5 & 7 \\
\hline 44 & $20-30$ & Anspach & 1.0 & Yes & Yes & No & 1.0 & Yes & Yes & 3 & Yes & 4 & 6 \\
\hline 45 & $10-20$ & Linvatec & 1.0 & No & Yes & No & 1.2 & No & No & 7 & No & & 9 \\
\hline 46 & $20-30$ & Skeeter & 1.0 & Yes & Yes & Yes & 1.5 & Yes & No & 9 & No & & 9 \\
\hline 47 & $50+$ & Anspach & 1.0 & Yes & Yes & Yes & 1.0 & Yes & Yes & 11 & Yes & 7 & 10 \\
\hline 48 & $50+$ & MedNext & 1.0 & Yes & Yes & No & 1.0 & No & No & 2 & Yes & 7 & $\begin{array}{c}7 \\
\text { (Continues) }\end{array}$ \\
\hline
\end{tabular}


TABLE I.

(Continued).

\begin{tabular}{|c|c|c|c|c|c|c|c|c|c|c|c|c|c|}
\hline Questionnaire & $\begin{array}{c}1 \\
\text { Implants } \\
\text { (n) }\end{array}$ & Drill $†$ & $\begin{array}{c}3 \\
\\
\text { Burr } \\
\text { Size† }\end{array}$ & \begin{tabular}{c}
\multicolumn{1}{c}{4} \\
Facial \\
Nerve
\end{tabular} & $\begin{array}{c}5 \\
\text { Chorda } \\
\text { Tympani }\end{array}$ & $\begin{array}{c}6 \\
\text { Round } \\
\text { Window }\end{array}$ & $\begin{array}{c}7 \\
\text { Size } \\
\text { Opening }\end{array}$ & $\begin{array}{c}8 \\
\text { Drill } \\
\text { Round } \\
\text { Window }\end{array}$ & $\begin{array}{c}9 \\
\text { Round } \\
\text { Window } \\
\text { Insertions }\end{array}$ & $\begin{array}{c}10 \\
\text { Image } \\
1\end{array}$ & Exposure & $\begin{array}{c}11 \\
\text { Image } \\
2\end{array}$ & $\begin{array}{c}12 \\
\text { Image } \\
3\end{array}$ \\
\hline 50 & $50+$ & Skeeter & 1.0 & Yes & Yes & Yes & 1.2 & Yes & No & 7 & Yes & 7 & 9 \\
\hline 51 & $50+$ & Medtronic & 1.0 & Yes & Yes & No & 1.2 & No & No & 9 & No & & 9 \\
\hline 52 & 10-20 & Anspach & 1.0 & Yes & Yes & Yes & 1.5 & Yes & Yes & 6 & No & & 8 \\
\hline 54 & 10-20 & Stryker & 1.0 & No & Yes & Yes & 1.0 & Yes & No & 13 & No & & 10 \\
\hline 55 & $50+$ & Anspach & 0.6 & Yes & Yes & No & 1.0 & No & No & 5 & No & & 10 \\
\hline
\end{tabular}

*Indicates surgeons who indicated that the facial recess exposure was adequate but who picked a cochleostomy location for the same image. These surgeons were excluded from data analysis for image 2 cochleostomy location.

†The smallest drill indicated by each surgeon was used for data analysis.

Briggs et al., ${ }^{9}$ the authors noted that inferior drilling relative to the round window membrane should be more likely to ensure an atraumatic scala tympani insertion, although histologic insertion data were lacking. The fact that the spiral ligament attaches closely to the anterior and superior aspects of the round window membrane makes this area a high risk for cochleostomy-related trauma.

The aim of this article was to assess the current surgical practices of a group of North American cochlear implant surgeons with regard to exposure and cochleostomy location for scala tympani cochlear implantation.

\section{MATERIALS AND METHODS}

A survey (Appendix) containing 12 questions was distributed among surgeons participating at the William House Cochlear Implant Study Club in Toronto, Canada on September 16, 2006. A total number of 100 copies of the two-page survey were dispersed among participants, and a short announcement was made asking every surgeon to participate. The survey contained questions about the annual number of cochlear implant surgeries performed, the type and manufacturer of the drilling system used, questions about how each surgeon usually drills the facial recess and the cochleostomy, and three intraoperative images depicting various views through the facial recess onto the promontory. For orientation, all three photographs clearly contained the pyramidal process, stapedius tendon, round window niche and membrane. Two of the three photographs also contained the incudostapedial joint and fossa incudis.

All participants were asked to return the survey before leaving the meeting venue. Both authors checked the questionnaires for validity. Specifically, a single answer clearly marked had to be present for more than half of the questions. Ambiguous markings of the answer sheet were rejected. A copy of the questionnaire is shown in the Appendix. Raw data are displayed in Table I.

In the data review, some surgeons used annotations to indicate multiple responses or deviations from the multiplechoice items provided for each question. This was commonly observed for questions 2 and 7. For the latter question, some surgeons indicated variable cochleostomy diameters for different cochlear implant manufacturers. In those cases, the smallest burr or cochleostomy size was chosen for further data analysis. One questionnaire (1 of $73,1.4 \%)$ was returned without specification of the annual number of implantations. Also, five surgeons $(6.8 \%)$ did not complete the second page of the two-page questionnaire.

Inconsistency was also observed within the surveys. Nine surgeons $(12.3 \%)$ indicated that the promontory exposure shown in question 11 was inadequate but then selected a cochleostomy location in the corresponding image. Those nine answers were excluded from the evaluation of the cochleostomy site for image 2 . One surgeon (1.4\%) indicated that the facial recess exposure was adequate, but then failed to specify a cochleostomy location in the following image. Data validity was also checked using cochleostomy locations of images 1 and 3. For image 1 (question 10, left ear), locations 1,2 , and 3 were considered primarily superior to the round window membrane. Locations 4 through 7 were considered to be predominantly anterior, while locations 8 through 14 were considered inferior to the round window. Since the round window niche was unavailable for exact classification of cochleostomy location in surgical image 2 (question 11), locations 1 through 3 were estimated to be superior; 4 through 6 intermediate; and 7 through 9 inferior. Image 3 (question 12), on the other hand, shows a full exposure of the promontory, and locations 9 , 10 , and 11 were considered inferior; 7 and 8 anterior; and 8 through 12 superior to the round window niche.

Seven of the 73 surgeons $(9.6 \%)$ had conflicting data, for example, selecting a superior cochleostomy location in one image and an inferior cochleostomy in the other one. It was presumed, in these cases, that right-left confusion between surgical images 1 and 3 existed.

The data were coded and entered in a computer-based spreadsheet (Microsoft Excel, Microsoft Corporation, Redmond, WA) and further statistical processing was performed using SPSS 11.0 (SPSS Inc., Chicago, IL). Significant relationships between variables were sought using Spearman's nonparametric correlation test. Statistically significant relationships were assumed for $P<.05$.

\section{RESULTS}

\section{Surgeon Characteristics}

A total number of 73 questionnaires were returned, whereas 18 had to be excluded from this evaluation due to data inconsistencies (either unavailable or conflicting data for images 1 and 3). Thus, 55 questionnaires showed proper data availability and consistency. Figure 1 graphically shows the tabulated responses for question 1 to 9 . Of the 55 valid questionnaires, $61.8 \%$ of the surveyed 


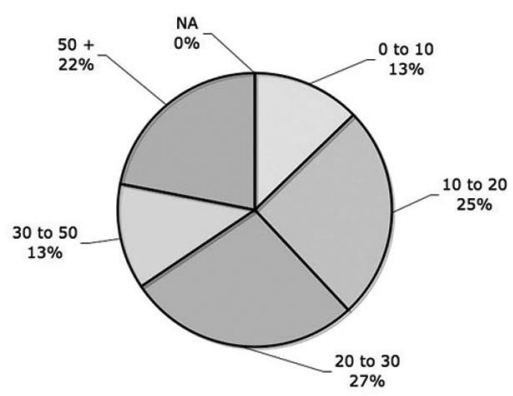

4: Do you routinely identify the facial nerve in the facial recess?

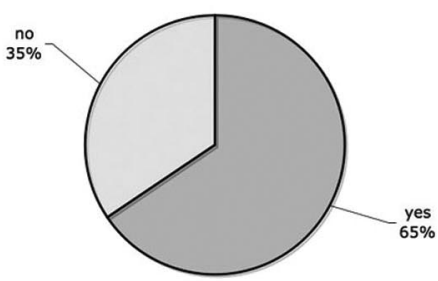

7: What size is your final cochleostomy?

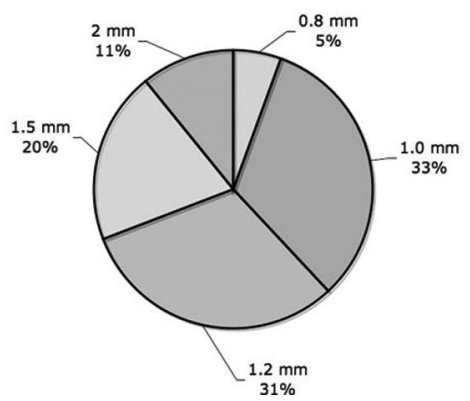

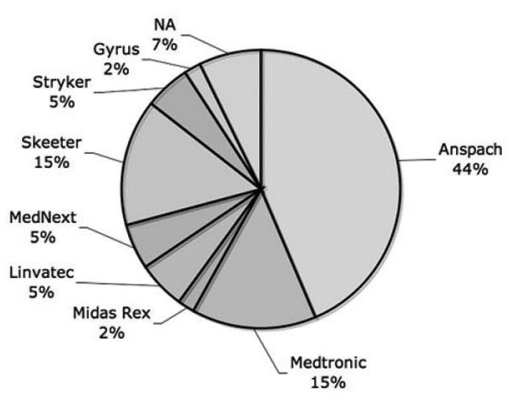

5: Do you routinely identify the chorda tympani?

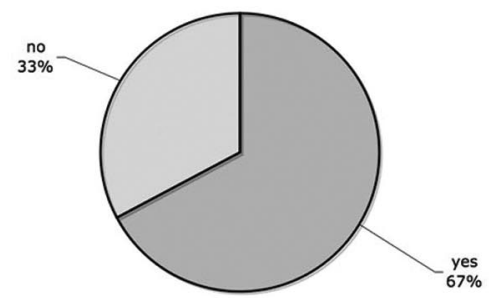

8: Do you sometimes drill through a part of the round window membrane?

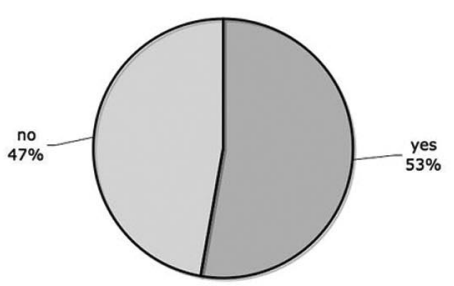

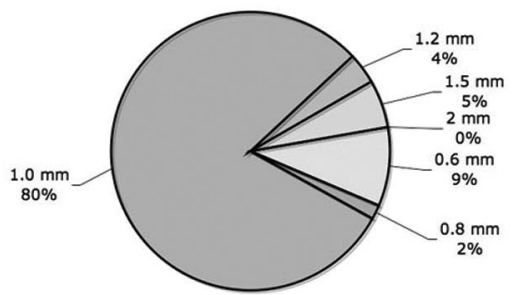

6: Do you routinely drill-off a part of the round windowniche overhang?

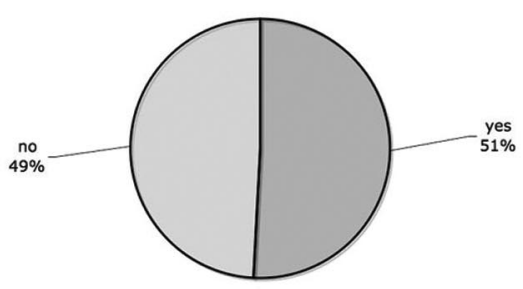

9: Do you sometimes perform round window insertions?

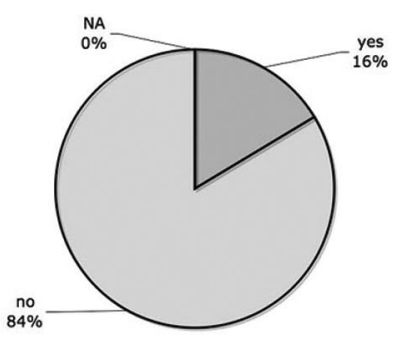

Fig. 1. Responses to questions 1 to 9 illustrated in pie graphs showing percentage distributions.

surgeons indicated that they perform more than $20 \mathrm{im}$ plants annually, making this a fairly experienced group.

\section{Exposing the Cochlear Promontory}

In terms of exposure, $34.5 \%$ of surgeons indicated that they do not routinely identify the facial nerve, and $32.7 \%$ do not identify the chorda tympani. Interestingly, $52.6 \%$ of surgeons that do not identify the facial nerve still identify the chorda tympani. Conversely, only $25.0 \%$ of surgeons who do identify the facial nerve do not usually identify the chorda tympani. In terms of round windowniche identification, question 11 showed an intraoperative, trans-facial recess exposure of the posterior mesotympanum that does not show the round window niche at all. Thirty-four percent of surgeons indicated that the exposure shown in this image was adequate for cochleostomy drilling and subsequently selected a location for placement.

\section{Round Window Membrane Identification}

After exposing the promontory, 50.9\% indicated that they routinely drill off a portion of the round window bony overhang (question 6) and $60.7 \%$ of these individuals routinely identify the facial nerve within the facial recess, while $67.9 \%$ identify the chorda tympani.

\section{Cochleostomy Location and Size}

Sixteen percent of respondents sometimes perform round window electrode insertions, and $52.7 \%$ of surgeons indicated that they sometimes drill through a part of the round window membrane during cochleostomy. Of those that sometimes utilize the round window membrane for access, $77.8 \%$ drill off a portion of the niche prior to insertion, and $77.8 \%$ drill through a portion of the round window membrane on occasion.

About $83.6 \%$ of surgeons do not use the round window membrane for electrode insertion, thus preferring a separate cochleostomy. The vast majority of these 

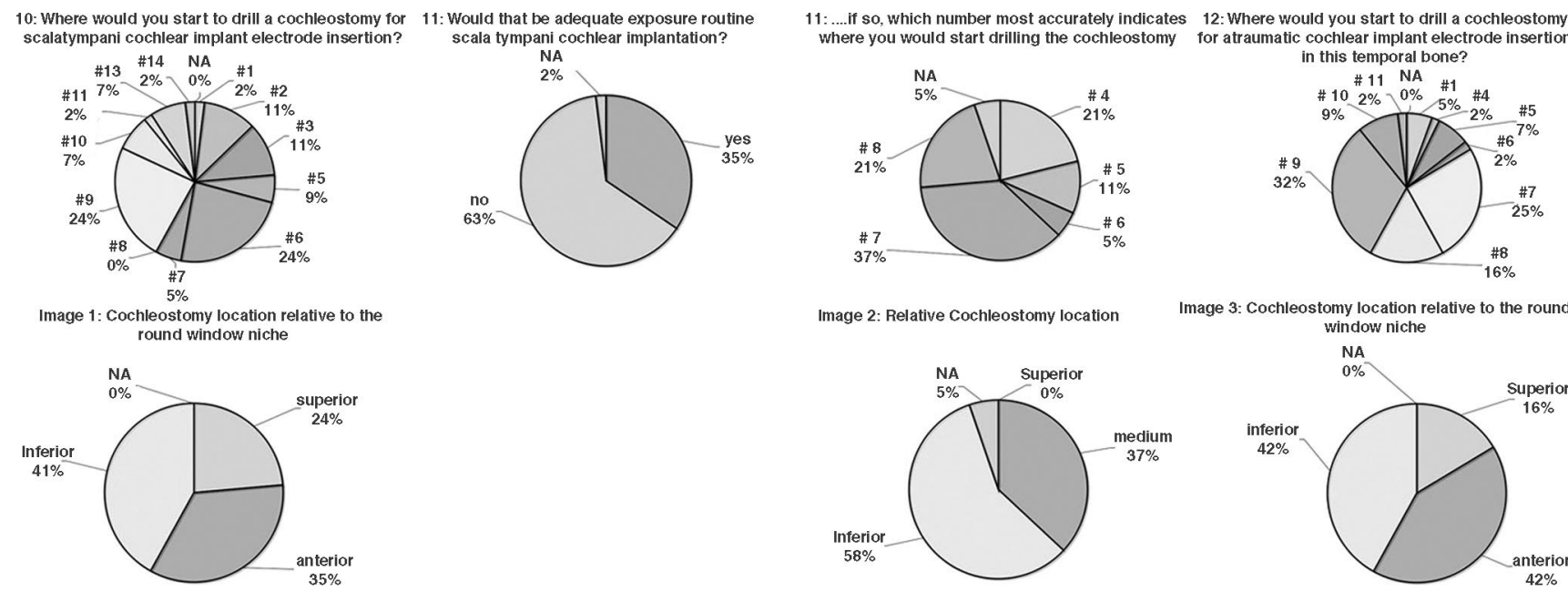

Image 2: Relative Cochleostomy location

Image 3: Cochleostomy location relative to the round
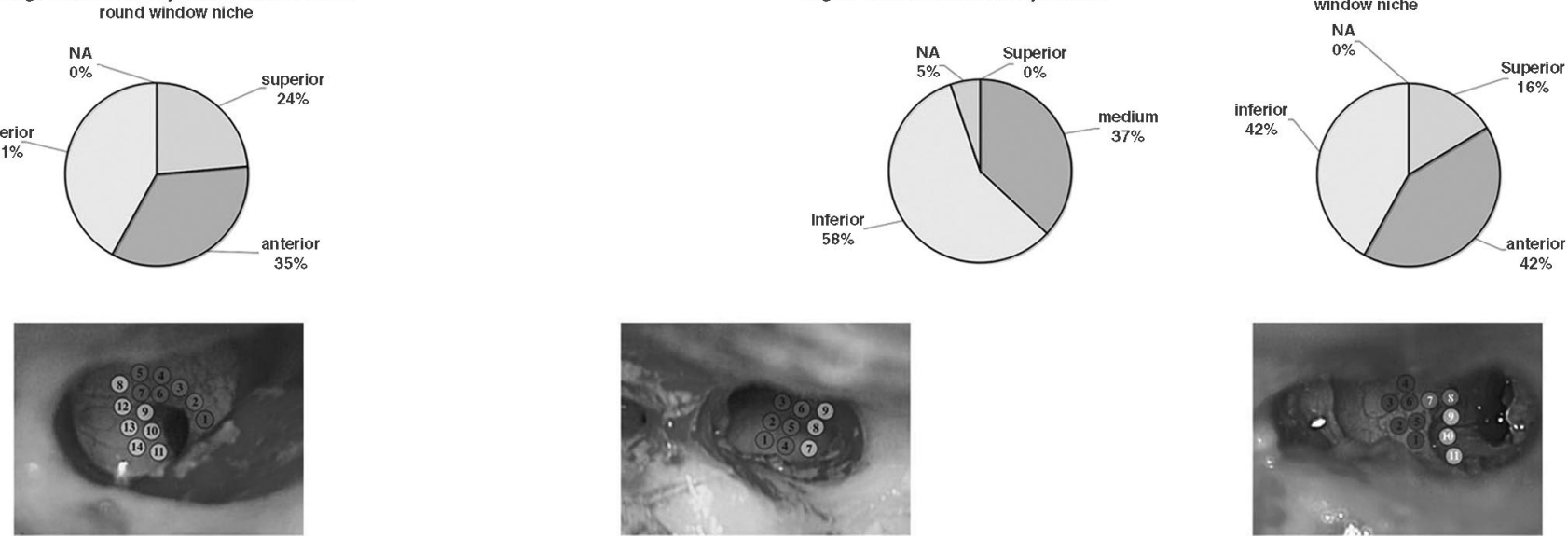

Fig. 2. Responses to questions 10,11 , and 12 of the survey illustrated via pie graphs showing the relative percentage values.

surgeons $(78.3 \%)$ indicated that they use a $1.0-\mathrm{mm}$ burr for drilling the cochleostomy. The remaining surgeons use a variety of burr sizes ranging from $0.6 \mathrm{~mm}$ to 1.5 $\mathrm{mm}$. Most surgeons also indicated that they usually drill a $1.0-\mathrm{mm}(32.7 \%)$ or a $1.2-\mathrm{mm}(30.9 \%)$ cochleostomy, although $10.9 \%$ make a $2.0-\mathrm{mm}$ cochleostomy opening. Forty-six percent of the surgeons who use a separate cochleostomy for electrode insertion also drill off a portion of the round window niche prior to insertion, while $47.8 \%$ drill through a portion of the round window membrane on occasion.

Detailed responses to the individual intraoperative images are illustrated in Figure 2. The bottom pie graphs summarize the selected cochleostomy locations.

Based on the cochleostomy classifications detailed in the Methods section, the majority of surgeons (76.4\%) selected an inferior or anterior cochleostomy location for image 1. Correspondingly, the majority of surgeons $(83.6 \%)$ also chose cochleostomy locations classified as either inferior or anterior in image 3. However, $23.6 \%$ and $16.4 \%$ of surgeons chose superior cochleostomy locations for images 1 and 3, respectively. Also, most (57.9\%) of the surgeons who indicated that the exposure in question 11 was adequate chose an inferior location for the cochleostomy.

\section{Correlations Between Surgical Images}

Seventy-eight percent of surgeons who selected an inferior cochleostomy in image 1 also chose an inferior location in image 3 , while the remaining $21.7 \%$ chose an anterior location in image 3. On the other hand, if surgeons selected a superior cochleostomy location in image $1,53.8 \%$ also chose a superior location in image 3 , while the remaining selected an anterior location. Again, surgeons who selected a superior location in image 1 and an inferior one in image 3 , or the reverse, were excluded from this evaluation.

In 37 participants, a good correlation between the surgical images was observed (for example, similar cochleostomy locations in images 1 and 3). Surgeons who used inferior cochleostomies also indicated that they drill smaller openings (mean cochleostomy diameters of 1.41 , 1.32 , and $1.14 \mathrm{~mm}$ for superior, anterior, and inferior locations, respectively). They were also more likely to drill the round window overhang $(43 \%, 50 \%$, and $78 \%$ for superior, anterior, and inferior locations, respectively) than surgeons who used superior cochleostomies. However, those differences did not reach statistically significant levels. Statistically significant levels were observed between question 11 (rating the exposure in image 2) and the cochleostomy location for images 1 and 3. Specifically, $83 \%$ of surgeons who selected superior cochleostomies rated the exposure in image 2 as adequate opposed to only $17 \%$ and $33 \%$ for surgeons selecting anterior and inferior locations, respectively.

\section{Influence of the Surgical Case Volume}

The number of implantations per year was correlated to the site of the cochleostomy in relation to the round window niche. Two of $12(16.7 \%)$ busy surgeons from the $50+$ group (who performed 50 or more implantations/year) used a superior cochleostomy in image 1 , and 1 (8.3\%) of these surgeons also selected a superior location in image 3 . In the group of non-busy surgeons (group 0-10 implantations/y, $\mathrm{n}=7$ ), $57.1 \%$ (4 of 7 ) and $28.6 \%$ ( 2 of 7 ) of 
surgeons selected superior cochleostomies in image 1 and 3 , respectively.

Also, the influence of surgical case volume on facial and chorda tympani nerve identification, round window niche drilling, and cochleostomy location was assessed. As expected, the percentage of busy surgeons $(50+$ group) who routinely identify the facial nerve was $91.7 \%$ (11 of 12). Respective numbers were $42.9 \%$ for those performing 30 to 50 implants/year, $66.7 \%$ for those doing 20 to 30 implants/year, $42.9 \%$ for the 10 to 20 implants/year group, and $85.7 \%$ for the group of surgeons with less than 10 implants/year. Similar values were seen for chorda tympani identification.

The percentage of surgeons drilling the round window overhang ranged from 28.6 to $71.4 \%$ with the value for busy surgeons of the $50+$ group being $50.0 \%$ and that for the inexperienced group (0-10 implants/y) being $28.6 \%$.

\section{Correlations Between Variables}

Correlations were calculated by means of nonparametric Spearman rank correlations. (Table II). Statistically significant relationships were present between the number of implantations per year (question 1 ) and the size of the cochleostomy burr (question 2, the more implants, the smaller the burr). Also, the number of implantations per year correlated with the size of the cochleostomy (question 7, the more implants, the smaller the cochleostomy) as well as the cochleostomy location in images 1 and 3 (superior cochleostomies with fewer implants per year). Further correlations were found between questions 3 (burr size) and 4 (identification of the facial nerve, the smaller the burr, the higher the likelihood of visualizing the facial nerve). Also, the burr size correlated with the size of the cochleostomy (question 7). Further correlations were found between questions 6 (round window overhang drill-off) and 8 (drill through the round window membrane, when drilling through the round window membrane, most surgeons also drill off the overhang) as well as between questions 6 and the cochleostomy location in image 3 (question 12 , superior cochleostomies more likely in surgeons who do not drill off the overhang). A clear correlation was found between surgical images 1 and 3 .

\section{DISCUSSION}

Results of this survey document the broad spectrum of surgical techniques for cochlear implantation in North America. Despite this clear variability among surgeons, some variables demonstrated statistically significant relationships. For example, the size of the burr used for cochleostomy drilling correlated with the final size of the cochleostomy opening. More interesting, a small number of annual implantations was associated with a superior cochleostomy location and larger final opening size. Thus, more experienced surgeons tended to drill smaller and more inferior or anteroinferiorly located cochleostomies than did their less experienced peers, although exceptions did exist. This probably relates to the fact that experienced surgeons possess a more thorough knowledge of the surgical anatomy of the region, thus requiring less bony excavation for creating a precise scala tympani opening.

TABLE II.

Calculated Correlations ( $P$ Values of Spearman Nonparametric Correlations) Between Variables.

\begin{tabular}{|c|c|c|c|c|c|c|c|c|c|c|c|}
\hline Variable & Variable Name & \multicolumn{10}{|c|}{ Correlation With } \\
\hline 1 & $\begin{array}{l}\text { Number of cochlear } \\
\text { implants/year (\#) }\end{array}$ & $.045^{\star}$ & .300 & .307 & .495 & $.006^{\star}$ & .550 & .223 & $.017^{\star}$ & .479 & $.049^{\star}$ \\
\hline 3 & $\begin{array}{l}\text { Burr size for the } \\
\text { cochleostomy (Burr) }\end{array}$ & & $.033^{\star}$ & .373 & .730 & $.001^{*}$ & .766 & .562 & .428 & .694 & .788 \\
\hline 5 & $\begin{array}{l}\text { Identification of the chorda } \\
\text { tympani (CT) }\end{array}$ & & & & .927 & .646 & .775 & .422 & .352 & .828 & .316 \\
\hline 6 & $\begin{array}{l}\text { RW overhang drill off } \\
\text { (RW OH) }\end{array}$ & & & & & .776 & $.022^{\star}$ & .081 & .185 & .781 & $.048^{\star}$ \\
\hline 7 & Cochleostomy size (Size) & & & & & & .241 & .624 & .122 & .428 & .066 \\
\hline 10 & $\begin{array}{l}\text { Cochleostomy location in } \\
\text { image } 1 \text { (Img 1) }\end{array}$ & & & & & & & & & .387 & $.000^{*}$ \\
\hline 11 & $\begin{array}{l}\text { Enough exposure in image } \\
2 \text { (Img 2) }\end{array}$ & & & & & & & & & & .143 \\
\hline 12 & $\begin{array}{l}\text { Cochleostomy location in } \\
\text { image } 3 \text { (Img 3) }\end{array}$ & & & & & & & & & & \\
\hline
\end{tabular}

*Statistically significant relationship $(P<0.05$ indicates statistical significance).

$\mathrm{FN}=$ facial nerve; Img = image; $\mathrm{RW}=$ round window; $\mathrm{RW} \mathrm{OH}=$ round window overhang. 
Why surgeons would choose a cochleosotomy location superior to the round window membrane remains unclear. Previous studies suggest that inferior or anteroinferior cochleostomy locations usually provide an atraumatic path for access into scala tympani. ${ }^{9}$ On the contrary, drilling superior to the round window membrane features relatively blind drilling on the cochlear promontory, and probable electrode misplacement into either scala vestibuli or the vestibule, depending on the angle of descent. Deeper drilling in this region could also result in unwanted entrance into the cochlear modiolus and, ultimately, the internal auditory canal.

Overall, uniformity in scala tympani cochleostomy placement is lacking. This probably has resulted from the general feeling that precise electrode location within the cochlea is unnecessary. Recent studies now suggest that electrode location should be within scala tympani, and that dislocations or placement of the array into scala vestibuli may result in worse outcomes. ${ }^{10,15}$ That scala vestibuli placements and cochlear duct transactions will produce a high likelihood of hearing loss also makes these locations unacceptable for hearing preservations surgeries. ${ }^{2}$ Careful temporal bone dissection is needed among implant surgeons. Moreover, the need for studies demonstrating the topographical, surgical anatomy, and cochleostomy locations with the resulting intracochlear histopathology is needed. Aggressive dissemination of such information is also needed to make surgeons aware of these important techniques.

\section{APPENDIX}

\section{PRESUMED LOCATION OF AN ATRAUMATIC COCHLEOSTOMY FOR COCHLEAR IMPLANTATION ....what answer fits best?}

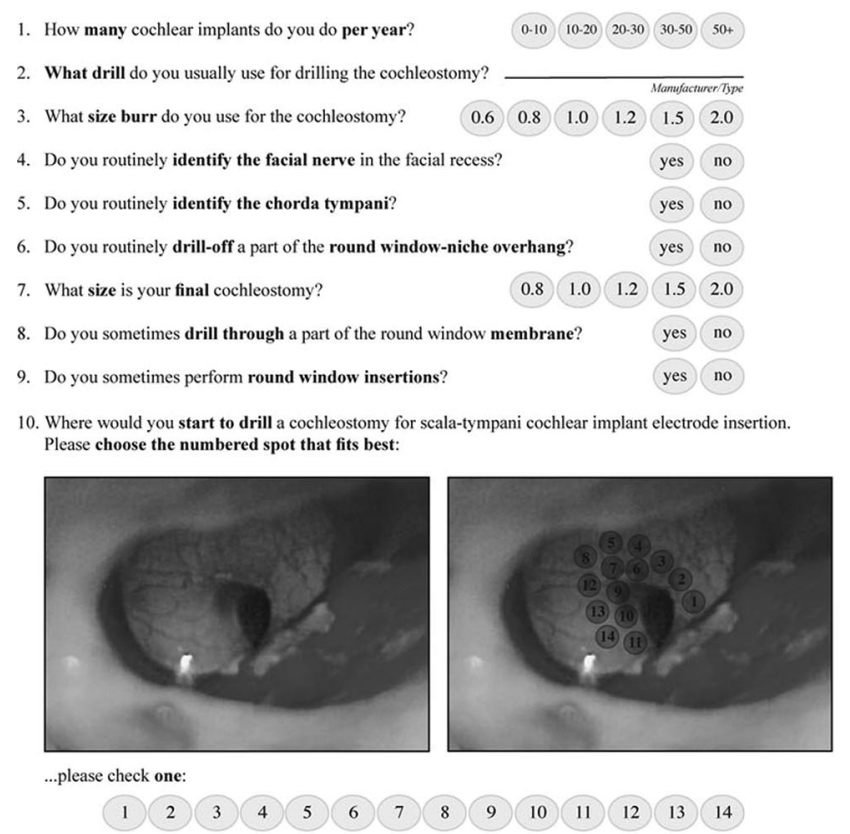

11. Would that be adequate exposure for routine scala tympani cochlear implantation? Yes No
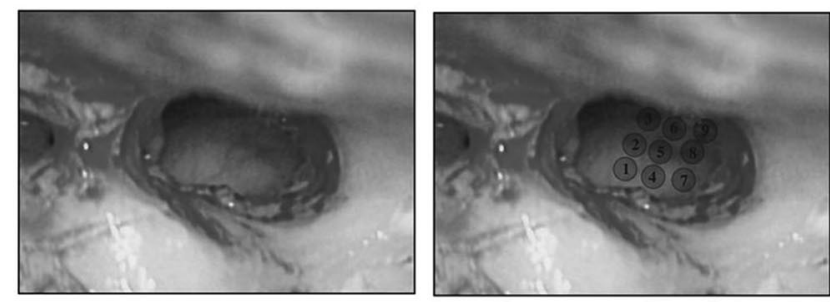

..if so, which number most accurately indicates where you would start drilling the cochleostomy:

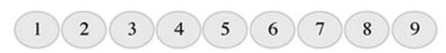

12. Where would you start to drill a cochleostomy for atraumatic cochlear implant electrode insertion in this temporal bone. Please choose the numbered spot that fits best:
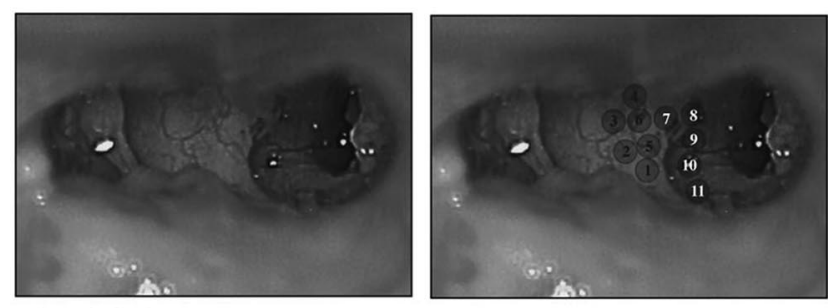

...please check one:

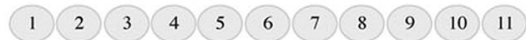

Questionnaire handed out during the William House Study Club in Toronto, Canada.

\section{BIBLIOGRAPHY}

1. Zrunek M, Lischka M, Hochmair-Desoyer I, Burian K. Dimensions of the scala tympani in relation to the diameters of multichannel electrodes. Arch Otorhinolaryngol 1980;229:159-165.

2. Adunka O, Kiefer J, Unkelbach MH, Radeloff A, Gstoettner W. Evaluating cochlear implant trauma to the scala vestibuli. Clin Otolaryngol 2005;30:121-127.

3. House WF, Urban J. Long term results of electrode implantation and electronic stimulation of the cochlea in man. Ann Otol Rhinol Laryngol 1973;82:504-517.

4. Banfai P. [A surgical approach for the cochlear implant (author's translation)]. Hno 1978;26:85-89.
5. House WF, Edgerton BJ. A multiple-electrode cochlear implant. Ann Otol Rhinol Laryngol Suppl 1982;91: $104-116$.

6. Clark GM, Tong YC. Multiple-electrode cochlear implant for profound or total hearing loss: a review. Med J Aust 1981; 1:428-429.

7. Gstoettner WK, Baumgartner WD, Franz P, Hamzavi J. Cochlear implant deep-insertion surgery. Laryngoscope 1997; 107:544-546.

8. Su WY, Marion MS, Hinojosa R, Matz GJ. Anatomical measurements of the cochlear aqueduct, round window membrane, round window niche, and facial recess. Laryngoscope 1982;92:483-486. 
9. Briggs RJ, Tykocinski M, Stidham K, Roberson JB. Cochleostomy site: implications for electrode placement and hearing preservation. Acta Otolaryngol 2005;125: $870-876$.

10. Aschendorff A, Kromeier J, Klenzner T, Laszig R. Quality control after insertion of the nucleus contour and contour advance electrode in adults. Ear Hear 2007;28:75S-79S.

11. von Ilberg C, Kiefer J, Tillein J, et al. Electric-acoustic stimulation of the auditory system. New technology for severe hearing loss. ORL J Otorhinolaryngol Relat Spec 1999;61:334-340.

12. Gantz BJ, Turner CW. Combining acoustic and electrical hearing. Laryngoscope 2003;113:1726-1730.
13. Adunka O, Unkelbach MH, Mack M, Hambek M, Gstoettner W, Kiefer J. Cochlear implantation via the round window membrane minimizes trauma to cochlear structures: a histologically controlled insertion study. Acta Otolaryngol 2004; 124:807-812.

14. Kiefer J, Pok M, Adunka O, et al. Combined electric and acoustic stimulation of the auditory system: results of a clinical study. Audiol Neurootol 2005;10:134-144.

15. Skinner MW, Holden TA, Whiting BR, et al. In vivo estimates of the position of advanced bionics electrode arrays in the human cochlea. Ann Otol Rhinol Laryngol Suppl 2007;197:2-24. 